\title{
O CONHECIMENTO ANATÔMICO AO ALCANCE DOS ALUNOS DE ENSINO MÉDIO DE ESCOLA PÚBLICA EM CATALÃO GOIÁS A PARTIR DE AULAS PROBLEMATIZADORAS
}

Marcos Paulo Batista de Assunção1; Lorrany Garcia Carneiro1; Ana Flávia Vigário²

${ }^{1}$ Graduando/a da Universidade Federal de Goiás. Regional Catalão. Catalão, GO, Brasil,marcospaulo.ufgbio@gmail.com.

${ }^{2}$ Docente da Unidade Acadêmica Especial de Biotecnologia. Núcleo de Ciências Biológicas, Universidade Federal de Goiás. Regional Catalão. Catalão, GO.

Recebido em: 06/04/2018 - Aprovado em: 10/06/2018 - Publicado em: 20/06/2018 DOI: 10.18677/EnciBio_2018A109

\begin{abstract}
RESUMO
Na formação docente, o estágio desempenha papel fundamental ao permitir que o estagiário vivencie experiências no ambiente escolar. Nele é observado o dia a dia da escola campo e, diante dos eixos propostos elabora-se um projeto de intervenção. A instituição no qual ocorreu sua aplicação é uma unidade escolar pública. Perante a necessidade de se abordar conteúdos relacionados à anatomia humana, o projeto buscou apresentar aos estudantes da segunda série do ensino médio da Educação de Jovens e Adultos (EJA), aspectos e informações importantes sobre o corpo humano. Para que fossem alcançados estes objetivos foi necessário ministrar quatro aulas problematizadoras e uma prática, aliadas à utilização de diferentes materiais didáticos (apresentação de slides e modelo anatômico). Durante a regência diversos contratempos ocorreram, mas foi possível alcançar os objetivos previstos. Antes da intervenção os alunos possuíam pouco conhecimento prévio sobre anatomia e fisiologia do corpo humano. Após as aulas a quantidade de respostas corretas foi de $58,2 \%$ além disso, durante a atividade prática verifica-se que os estudantes haviam entendido qual é a localização de cada órgão e suas respectivas funções. Assim, com esses resultados o papel dos professores está em mediar o conhecimento no processo de ensino e aprendizagem, de modo que os saberes se aproximem da realidade na qual a escola campo está inserida.
\end{abstract}

PALAVRAS-CHAVE: anatomia humana, aulas problematizadoras, estágio curricular supervisionado.

\section{THE ANATOMICAL KNOWLEDGE WITHIN REACH OF HIGH SCHOOL STUDENTS OF PUBLIC SCHOOLS IN CATALÃO - GOIÁS FROM PROBLEMATIZING CLASSES}

\begin{abstract}
In teacher training, the internship plays a fundamental role in allowing the trainee to live experiences in the school environment. In it is observed the day to day of the school and, in front of the proposed axes, a project of intervention is elaborated. The institution in which occurred the application is a public school unit. Due to the need of addressing contents related to the human anatomy, the project aimed to present to the second grade, high school students of Youth and Adult Education Program
\end{abstract}


(YAEP), important aspects and information about the human body. To achieve these objectives, it was necessary to apply four problem-solving classes and one practice, combined with the use of different teaching materials (slideshow presentations and the anatomical model). During the regency several setbacks occurred, but the objective was partially achieved. Before the intervention the students had little prior knowledge about human anatomy and physiology. After the classes the number of correct answers was $58.2 \%$. In addition, during the practice it was noticed that the students had understood what is the location of each organ and its respective functions. Therefore, with these results we notice that is up to us teachers the role of mediate the knowledge in teaching and learning processes, so that the knowledge gets closer to the reality in which the school is inserted.

KEYWORDS: supervised curricular internship, human anatomy, problematizing classes.

\section{INTRODUÇÃO}

Os processos de apropriação dos conhecimentos que contribuem como pilar ao ofício como docente é frequente e, através do curso de licenciatura em Ciências Biológicas, é possível perceber a dificuldade encontrada pelo alunado em lidar com a realidade da sala de aula. Pelozo (2007) em uma de suas publicações destaca que nos cursos de formação de professores a "Prática de Ensino" assume uma posição de destaque na grade curricular, uma vez que a mesma proporciona um elo entre as demais disciplinas do curso, conciliando a teoria à prática docente e possibilitando a reflexão científica.

$\mathrm{Na}$ formação docente, o estágio é uma ferramenta essencial para formação do licenciando, pois o permite oportunidades de vivenciar a realidade dentro de uma sala de aula e o mesmo deve transceder a mera obrigação curricular assumindo uma função protagonista em meio à formação inicial (MACIEL; MENDES, 2010). A experiência do estágio é essencial para a formação integral do aluno, considerando que cada vez mais são requisitados profissionais com habilidades e bem preparados. Ao chegar à universidade o aluno se depara com o conhecimento teórico, porém muitas vezes é difícil relacionar teoria e prática se o estudante não vivenciar momentos reais em que será preciso analisar o cotidiano (MAFUANI, 2011). Além disso, o estágio é uma via que proporciona a troca de conhecimentos e vivências entre os alunos da escola, aluno-estagiário e os funcionários. Seu principal objetivo é proporcionar aos discentes o contato com os instrumentos e situações de preparação para a introdução e inserção no mercado de trabalho, mediante ao ambiente de aprendizagem adequado e acompanhamento pedagógico supervisionado pelo professor em sala de aula (SANTOS, 2014).

Segundo a LDB, Lei de Diretrizes e Bases da Educação Nacional, n 9394/96 o estágio supervisionado é uma obrigatoriedade nos cursos de licenciatura nacionais. Ele deve proporcionar a complementação do ensino e da aprendizagem, sendo planejados, executados, acompanhados e avaliados em conformidade com os currículos referências e calendários escolares, na perspectiva de instrumentos de integração, em termos de treino prático, de aperfeiçoamento técnico-culturalcientífico e de relacionamento humano (BRASIL, 1996).

$\mathrm{Na}$ Universidade Federal de Goiás a ementa do curso licenciatura em Ciências Biológicas exige, a partir regulamentação do Conselho Nacional de Educação - RESOLUÇÃO CNE/CP 2, DE 19 DE FEVEREIRO DE 2002, que o licenciado curse quatro estágios supervisionados com a carga horária total de 400 horas, conforme a legislação nacional. Os estágios curriculares I e II são 
desenvolvidos no Ensino Fundamental e os estágios III e IV desenvolvidos no Ensino Médio, sendo que nos Estágios I e III ocorre a observação e a elaboração de projetos de ensino e no II e IV são destinados à regência com o desenvolvimento e aplicação dos projetos.

Os saberes concernentes à área biológica são desenvolvidos nas escolas de educação básica através das disciplinas Ciências (no ensino fundamental - do primeiro ao nono ano) e Biologia (no ensino médio - do primeiro ao terceiro ano). As metas que estas disciplinas se propõem para o ensino desta área científica, são: mostrar como o conhecimento colabora para a compreensão do mundo e suas transformações, reconhecer o homem como parte do universo e como indivíduo, proporcionar a todos os cidadãos os conhecimentos e oportunidades de desenvolvimento de capacidades necessárias para se orientarem em uma sociedade complexa e permitir a compreensão do que se passa à sua volta para tomada de decisões que intervenham em sua realidade (BRASIL, 1998; CHASSOT, 2003).

Assim, entende-se que o ensino das ciências biológicas na educação básica deve abranger não somente o aprendizado dos conceitos das Ciências Naturais, mas também sua aplicação a situações práticas, permitindo a compreensão das relações entre ciência e sociedade e dos mecanismos de produção e apropriação dos conhecimentos científicos e tecnológicos (FRACALANZA et al., 1987). Além disso, o ensino de Biologia envolve a análise das consequências sociais e culturais do desenvolvimento científico e tecnológico, proporcionando o estabelecimento das relações entre desenvolvimento, progresso social e melhoria da qualidade de vida (TRIVELATO, 1995).

Um dos conteúdos que constituem a grande área das Ciências Biológicas é a Anatomia Humana, área essa que trata de conhecimentos relacionados aos diferentes sistemas do corpo. O conhecimento anatômico no ensino escolar é importante para que o aluno compreenda os primórdios de suas descobertas, que o corpo se altera com a passagem do tempo, com mudanças de hábitos alimentares e de vida, com possibilidades distintas de prazer e de desejo ou com novas formas de intervenção médica e tecnológica. Dessa forma, na adolescência, para se obter respostas e orientação significativa quanto a esses assuntos, é necessário primeiramente a introdução da Anatomia Humana na disciplina escolar (SILVA; CICILLINI, 2008).

A partir do que foi mencionado durante todo o contexto e conhecendo as dificuldades da escola campo em relação à carência de laboratórios para o ensino de Biologia, o intuito da proposta de ensino para o estágio IV objetivou que na atividade desenvolvida ocorresse a abrangência do conhecimento anatômico científico, através de uma transposição em aula expositiva dialogada e aula prática, facilitando a compreensão do referente conteúdo de forma que os alunos se integrem nesse processo de ensino aprendizagem considerando seus conhecimentos prévios. Em geral, os conteúdos trabalhados atende de forma direta ao cronograma do Currículo Referência do Estado de Goiás (SEDUCE, 2012), abordando a aprendizagem no intuito de promover o melhor aprendizado dos estudantes.

\section{RELATO DE CASO}

As regências ocorreram no âmbito escolar de uma escola pública em Catalão Goiás. Antes (no Estágio Curricular Supervisionado III) de começar a aplicação do projeto houve o reconhecimento da instituição (como são organizadas as aulas, 
salas e metodologia de ensino) assim como a observação de algumas aulas de Biologia.

Após o reconhecimento do colégio e das turmas, a ministração dos conteúdos ocorreu por meio de uma sequência didática de quatro aulas (Apêndice $A$ e $B$ ). As atividades desenvolvidas, visando um bom desempenho no processo de ensinoaprendizagem a partir das aulas problematizadoras, foram aplicadas em uma turma de $2^{a}$ Série do Ensino Médio do EJA na escola campo. Esta turma era composta por 15 alunos com faixa etária variando de 18 a 57 anos. O eixo temático escolhido teve como base o conhecimento anatômico ao alcance dos estudantes de ensino médio da rede pública de ensino em Catalão - Goiás a partir de aulas problematizadoras a qual puderam ser observadas durante o Estágio Curricular Supervisionado III.

Para avaliar o aproveitamento da regência, minutos antes da primeira aula ocorreu a aplicação de um pré-teste (Apêndice $C$ ), para que fosse possível compreender o conhecimento prévio dos alunos acerca do tema deste projeto. Este questionário continha dez perguntas de múltipla escolha que eram voltadas para o tema que a ser ministrado posteriormente. O mesmo questionário foi aplicado novamente ao termino da última aula na intervenção. Com esse método possibilitou analisar o desenvolvimento destes após todas as atividades realizadas sobre 0 tema, bem como o aproveitamento dos estudantes após a intervenção. Uma avaliação do trabalho desenvolvido pelos estagiários também foi feita com o objetivo de conseguir um feedback da postura como futuros docentes. Esta apresentava três questões de múltipla escolha e uma questão discursiva.

Para a explicação do conteúdo foi utilizada a apresentação de slides (Apêndice E) no programa PowerPoint, quadro negro e giz. Esta apresentação continha ilustrações e esquemas sobre o conteúdo abordado. Segue abaixo como ocorreu os quatro momentos de aplicação das regências:

No primeiro momento, apresentou-se uma breve introdução sobre a história da anatomia humana, abordando o conceito etimológico da palavra e também expondo os níveis de organização dLos seres vivos. Após a parte introdutória dos conceitos breves em anatomia, foi aberto um dialogo com a turma de forma indagadora, sobre quais orgãos são constituintes do corpo humano, sua localização e quais eram suas funções no organismo. Neste primeiro momento da discursão possíbilitou observar o conhecimento prévio que os estudantes possuíam. Durante o dialogo busou-se associar o conteúdo em questão com o dia-a-dia e foram esclarecidas dúvidas sobre assuntos como, por exemplo, a má digestão. Com essa metodologia conseguiu-e observar e caracterizar a importância do conteúdo trabalhado, uma vez que os alunos participaram com perguntas e interação.

Seguiu-se com as aulas teóricas as quais foram ministradas de forma expositiva, destacando sempre de maneira objetiva e clara, os sistemas do corpo humano separadamente. Foi abordado de início o sistema circulatório, os nomes de suas estruturas e suas devidas funcionalidades, sempre indagando o aluno com perguntas problemarizadoras sobre o assunto. $\mathrm{Na}$ seguência, os conteúdos referentes ao sistema respiratório e ao sistema digestório foram abordados, também de forma expositiva. A localização e funcionalidades dos orgãos que compõem esse sistema foi explorado através de imagens. Em seguida, os alunos foram questionados a respeito do processo de digestão, esse tipo de acontecimento foi questionado pelo fato de ser próximo a realidade do alunado fazendo com que ele o associe com seu cotidiano e levantando questionamentos.

No que se refere ao sistema respiratório, houve uma aula teórica, onde também através de figuras apresentou-se a constituição deste sistema, destacando 
o nome de suas estruturas e funcionalidades, trazendo para mais próximo dos estudantes o processo de respiração e a partir de problematizações o que ocasiona a embolia pulmonar, caso que acomete grande parte da população nos dias de hoje.

Por fim para finalizar a parte teórica, assuntos relacionados à anatomia funcional do sistema reprodutor masculino e feminino foram trabalhados, uma vez que o estudo da anatomia é visual e tátil. Imagens que contemplam o sistema reprodutor dos diferentes seres humanos foram projetadas juntamente com as estruturas anatômicas que compõe o sistema e as funções desempenhadas no corpo. Através desta abordagem notou-se que houve um maior interesse pelos alunos, de modo que foram levantados questionamentos e curiosidades sobre o próprio corpo.

Em todas as aulas apresentaram-se algumas situações que ocorrem no nosso cotidiano, como por exemplo: "como um alimento é processado no corpo até o momento de excreção? como ocorre a respiração?" e também sobre diversas patologias relacionadas os orgãos trabalhados.

Para concluir e finalizar o projeto, foi proposto uma prática contemplando todo o conteúdo exposto e questionado na teoria. Foi criada uma situação-problema e transformado o ambiente da sala de aula em uma "sala de cirurgia" que haviam dois pacientes, de forma figurativa, onde os mesmos eram representados por torsos anatômicos (disponibilizados pela Universidade Federal de Goiás, Regional Catalão - UFG/RC). Os referentes torsos anatômicos ficaram expostos sobre as mesas e cobertos por panos branco. Foi proposto que os "pacientes" passassem, de imediato, por um transplante de órgãos, sendo que estes já estavam separados em uma mesa auxiliar.

A turma foi dividida em dois grupos. Cada grupo ficou responsável para desempenhar o papel de um "cirurgião", contando com o auxílio do médico responsável (função exercida pelos professores estagiários). Para a execução desse procedimento todos os orgãos deveriam ser transplantados e interligados corretamente, caso contrário o transplante não seria um sucesso e levaria o "paciente" a óbito. Vale ressaltar que, enquanto os estudantes tentavam interligar cada orgão em seu respectivo lugar, os estagiários sempre indagavam o aluno com perguntas sobre determinadas estruturas e sua função no organismo.

Em geral, a prática abordada teve como finalidade colocar em prática todo o conhecimento que foi ministrado durante as aulas teoricas. Após os grupos terem trabalhado corretamente, interligando e associando as peças anatômicas didáticas em seus devidos lugares, foi distribuído para cada aluno o pós teste e avaliação dos estagiários. Já com todos os dados em mãos, procedeu-se a análise e tabulação dos dados obtidos no pré e pós-teste, utilizando para isso o programa Microsoft Excel 2010 e representando os resultados por meio de gráficos.

\section{RESULTADOS E DISCUSSÃO}

O grupo amostral deste relato de experiência foi composto por quinze alunos. No entanto, somente onze participaram de ambos os testes. Para avaliação do conhecimento prévio sobre o tema proposto foi aplicado um pré-teste antes de iniciar as aulas e para verificação final, um pós-teste foi aplicado após a sequência didática. Dessa forma, os dados obtidos serão apresentados a seguir.

Analisando a Figura 1 observa-se que os estudantes possuíam um conhecimento prévio referente a organização dos seres vivos, tema da questão 1, já 
que $81,8 \%$ (9 estudantes) acertaram qual era a alternativa correta, enquanto que após a intervenção esse percentual subiu para 90,9\% (10 alunos).

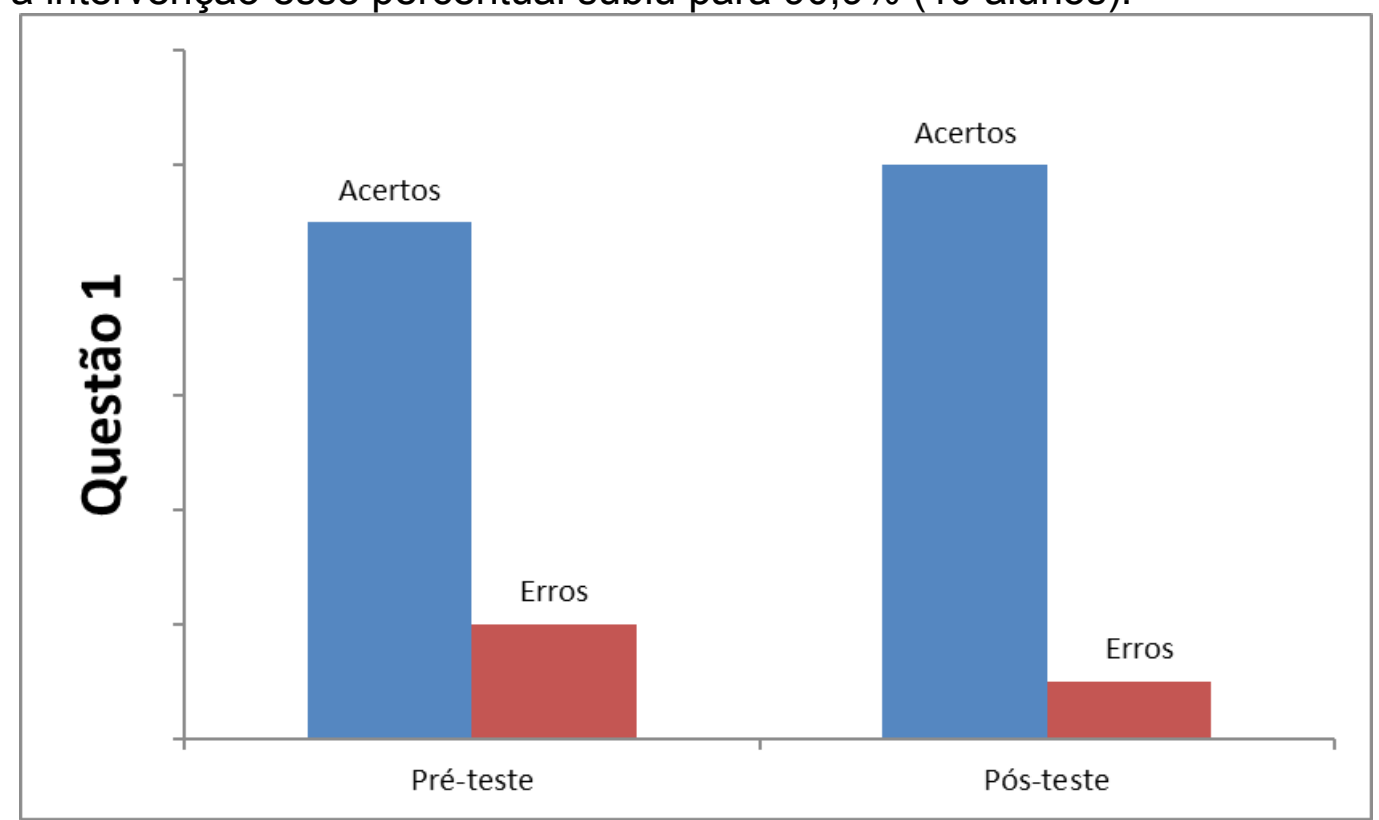

FIGURA 1: Gráfico referente à quantidade de acertos e erros na questão 1 do pré e pós-teste aplicados aos estudantes do $2^{\circ}$ ano da turma do EJA

Os órgãos que compõem o sistema digestório também foram abordados no questionário. Essa questão após a ministração das aulas foi respondida corretamente por todos os estudantes, sendo que anteriormente cerca de $9,1 \%$ da turma havia respondido errado (Figura 2).

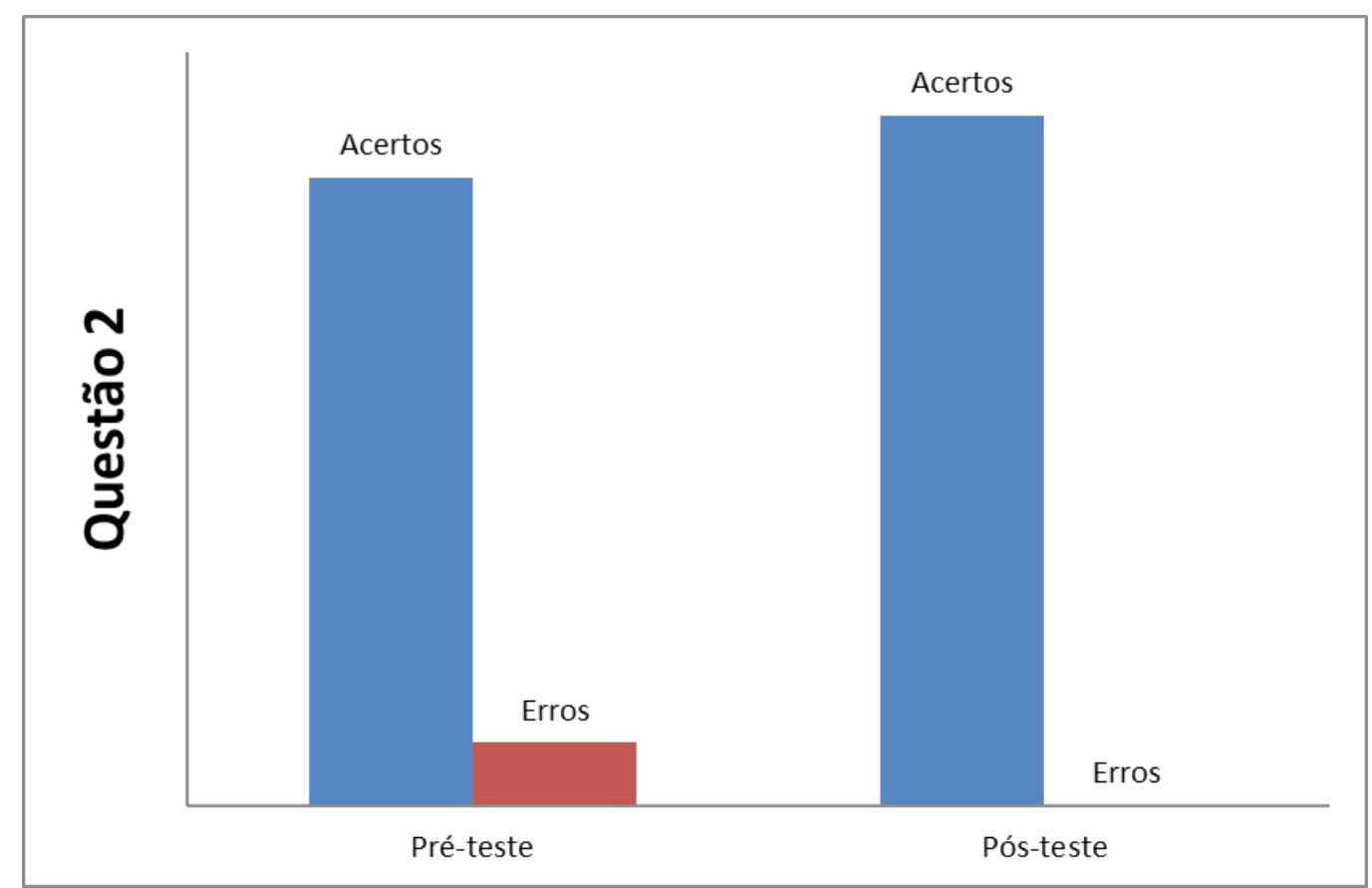

FIGURA 2: Quantidade de acertos e erros na questão 2 do pré e pós-teste aplicados aos estudantes do $2^{\circ}$ ano da turma do EJA.

O coração é um órgão que faz parte do sistema cardiovascular cujas funções são fundamentais para a vida. Compreendendo isso, no questionário havia uma 
pergunta (questão 3) sobre o mesmo e o processo da circulação sanguínea. Essa questão não obteve nenhuma alteração na quantidade de acertos e de erros tanto no pré quanto no pós-teste de modo que, houve $54,5 \%$ de acertos e 45,5 de erros em ambos os questionários. Talvez esse resultado tenha se mantido, pois o enunciado da questão era extenso assim exigindo mais tempo para a compreensão.

Questões relacionadas a variações anatômicas também foram abordadas nos testes, cuja primeira pergunta era sobre uma característica dessa variação. Nesta questão houveram erros, tanto antes (10 estudantes) quanto após (8 alunos) a intervenção, mas houve uma elevação do índice de acertos, $18,2 \%$, do pós-teste (Figura 3). A alta incidência de erros talvez se explique por conta da presença de termos científicos nas alternativas ou ainda ao fato do assunto não ser tão abordado no ambiente escolar.

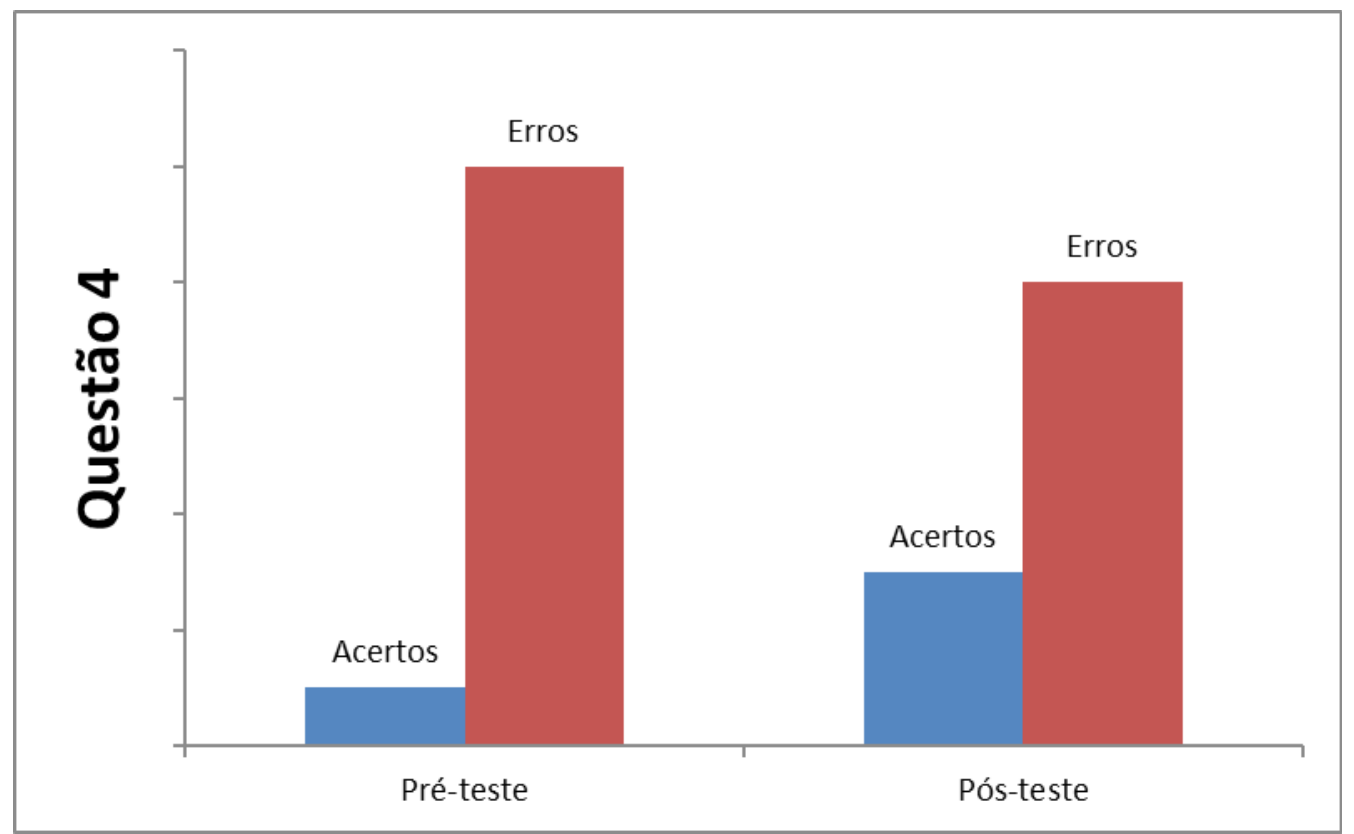

FIGURA 3: Gráfico referente à quantidade de acertos e erros na questão 4 do pré e pós-teste aplicados aos estudantes do $2^{\circ}$ ano da turma do EJA.

Ainda com relação a variação anatômica, no enunciado da questão 5 foi colocado da seguinte forma: entre os fatores gerais de variação anatômica, o que envolve a constituição física do indivíduo denomina-se. Nessa pergunta, os alunos também mantiveram a mesma quantidade de erros $(63,6 \%)$ e acertos $(36,4 \%)$ em ambos os questionários. Resultado este que reforça que os estudantes ainda possuem dificuldade na compreensão do tema.

Segundo Guedes (2015) diversos fatores influenciam na deficiência do processo de ensino e aprendizagem em relação ao ensino de anatomia nas escolas, sendo que os principais são: desarticulação com o cotidiano e as dificuldades de uma maior elucidação dos assuntos encontradas por parte dos discentes. A interferência da aula prática também aparece na resolução da questão 4 (Figura 4). Tendo em vista que o assunto foi explicado e mostrado as estruturas durante a sua execução. Anteriormente, o conhecimento prévio dos alunos em relação aos órgãos reprodutores era menor, ocasionando em $45,5 \%$ de acertos. Após a execução da aula pratica houve um discreto aumento no índice de acertos, para $54,5 \%$, enquanto que os erros caíram $9 \%$. 


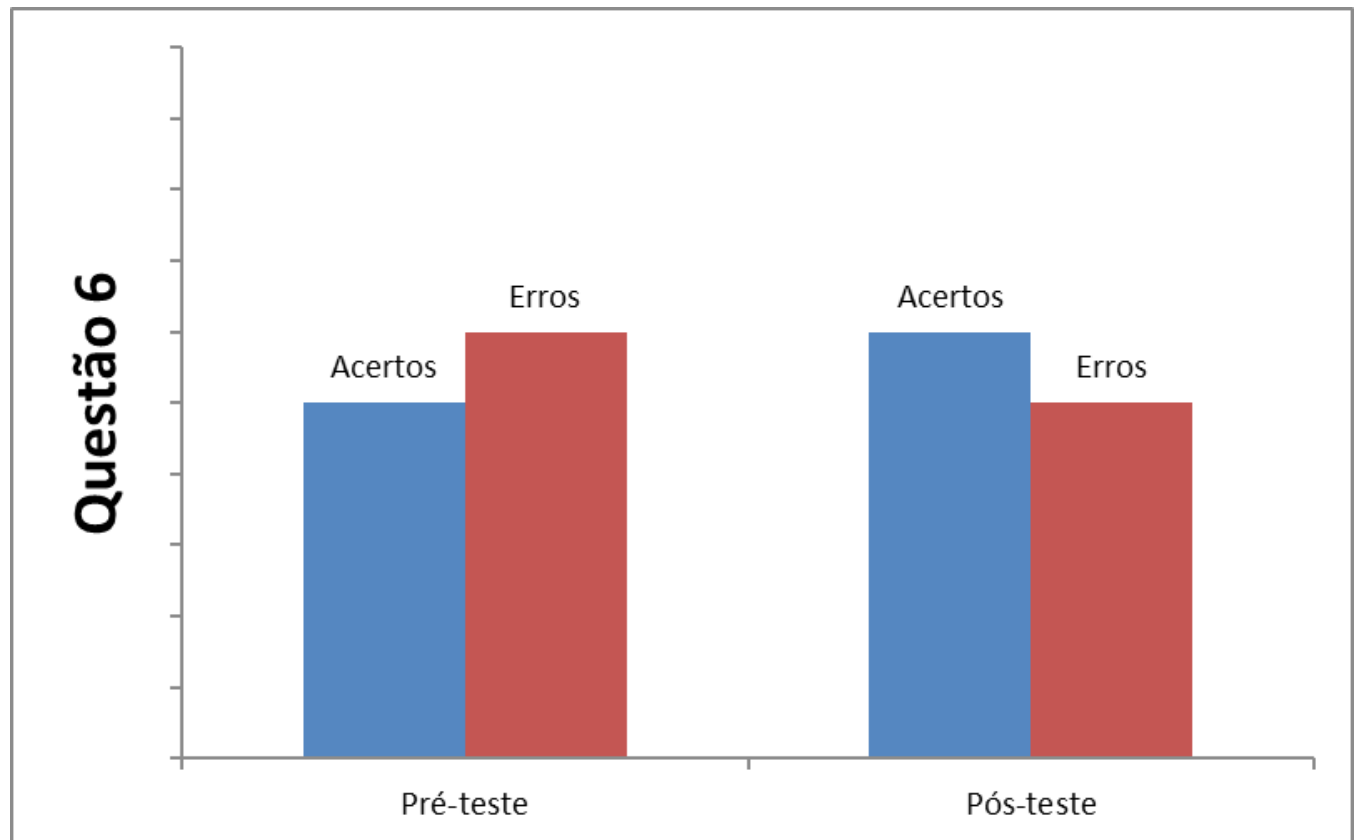

FIGURA 4: Gráfico representativo da quantidade de acertos e erros na questão 6 do pré e pós-teste aplicados aos estudantes do $2^{\circ}$ ano da turma do EJA.

Assim como outras questões anteriores, na pergunta referente ao sistema circulatório (questão 7) os alunos conservaram a mesma quantidade de acertos $(72,7 \%)$ e erros $(27,3 \%)$ nos dois questionários aplicados antes e após a intervenção. A pergunta era bem simples e considerada fácil em comparação com outras, mas esse resultado nos coloca em alerta para o que Barbosa et al., (2010, p.1) frisam em seu trabalho:

O sistema circulatório, devido a sua complexidade, deve ser trabalhado de maneira clara, didática e dinâmica. É necessário que o professor busque abordagens diferenciadas para lecionar o conteúdo.

O conhecimento prévio dos estudantes em relação à função do intestino grosso, questão 8, era minimizado de modo que somente um aluno acertou a resposta. Após a ministração das aulas esse número subiu, registrando que 7 alunos acertaram qual era a alternativa correta. Com isso, se consta um aumento expressivo de $54,5 \%$ nos acertos e queda de $54,5 \%$ na porcentagem de erros (Figura 5). 


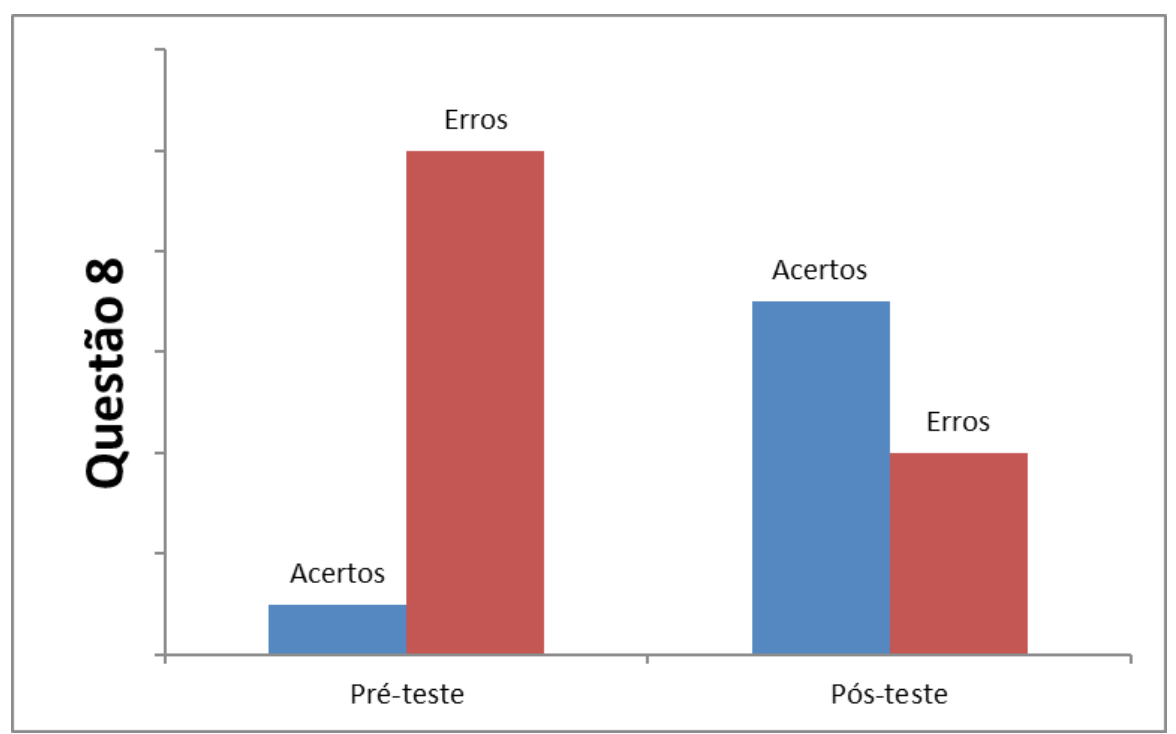

FIGURA 5: Gráfico referente à quantidade de acertos e erros na questão 8 do pré e pós-teste aplicados aos estudantes da $2^{\circ}$ série da turma do EJA.

$\mathrm{Na}$ questão 9 houve uma pequena decaída de 9,1\% na quantidade de respostas erradas na questão 9 do pós-teste $(72,7 \%)$ quando comparados aos erros no pré-teste $(81,8 \%)$. Já os acertos subiram de $18,1 \%$ para $27,3 \%$ (Figura 6 ). Esse baixo percentual de acertos, mesmo após a ministração do conteúdo, pode ser explicado devido ao fato das aulas terem "fugido" da rotina dos estudantes. Isso porque, o professor de biologia costuma utilizar somente o quadro-negro e o livro didático. Nesse contexto Evaristo et al. (2013) expõem acerca do uso do livro didático:

[...] Esta postura tomada pelo professor faz com que os alunos fiquem limitados apenas ao livro e como consequência estes não serão estimulados a pesquisar em outras fontes, tomando as informações presentes no mesmo como corretas, entretanto trabalhos como o de Brito et al. (2011) apontam que os livros podem trazer informações errôneas sobre a nomenclatura anatômica e imagens pouco claras e descritivas que podem confundir e levar ao não entendimento ou ao entendimento errado dos conteúdos.

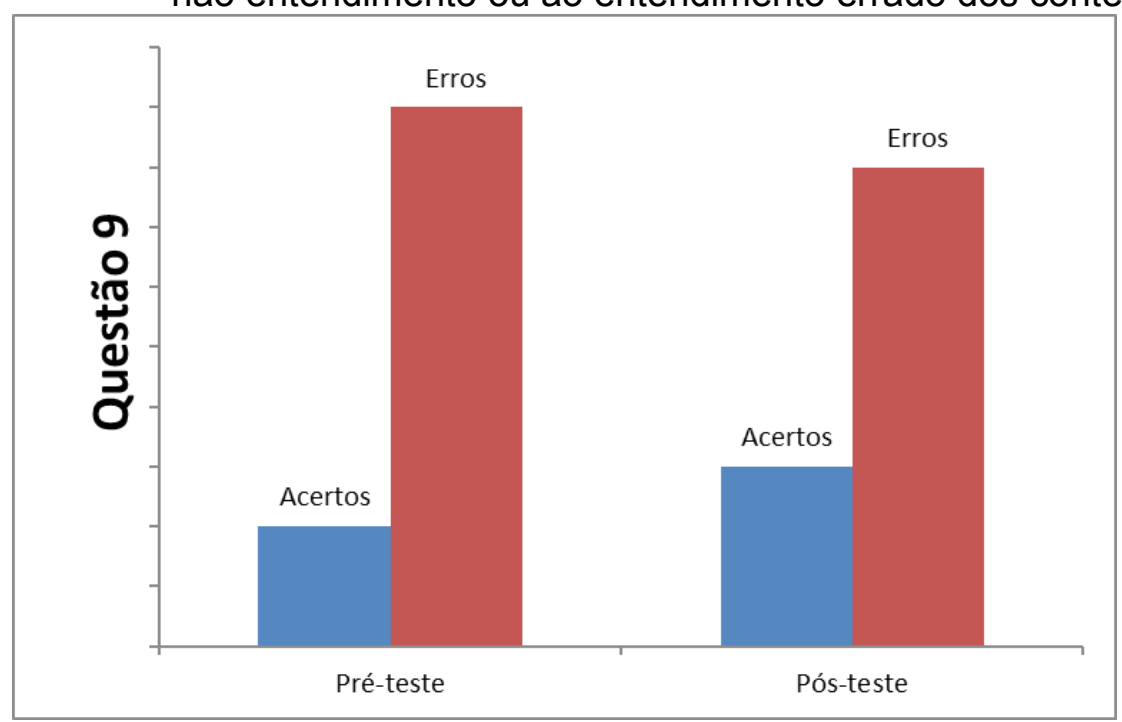

FIGURA 6: Gráfico referente à quantidade de acertos e erros na questão 9 do pré e pós-teste aplicados aos estudantes do $2^{\circ}$ ano da turma do EJA. 
Como estão acostumados a ter acesso a um material repleto de texto e com as aulas da intervenção tiveram que se deparar com outro material que possui mais imagens e esquemas e tiveram dificuldade em assimilar de imediato o que é explicado. Contudo, a utilização de slides é um excelente aliado para as aulas visto que "[...] os slides permitem uma projeção de alta resolução, enfatizando cores, beleza e detalhes, visíveis de qualquer ponto de uma sala de aula" (FERNANDES, 1998 citado por FREITAS, 2013, p. 14).

Freitas (2013) ainda salienta que há fatores negativos que prejudicam seu uso, tais como: falta de iluminação adequada para uma boa visualização do conteúdo exposto, ausência de profissionais que sabiam utilizar de maneira correta o data-show e o alto custo. Neste sentido, tudo isso faz com que muitas escolas evitem a aquisição deste aparelho.

$\mathrm{Na}$ décima questão ocorreu uma visível elevação na porcentagem de acertos após a intervenção. Antes das aulas foram registrados $90,9 \%$ de erros e $9,1 \%$ de acertos. Já após as explicações do conteúdo o percentual de acerto subiu para $54,5 \%$ e de erros caiu para 45,5\% (Figura 7). Essa grande quantidade de erros averiguados no pré-teste é o retrato de uma das dificuldades apresentadas no ensino de Anatomia e Fisiologia Humana. Para que a sua abordagem ocorra de forma adequada e eficiente é necessário a implementação de metodologias que possibilitem aos alunos manipular e identificar onde cada órgão constituinte do sistema em estudo situa-se no corpo humano (GUEDES, 2015). A aplicação dessa metodologia foi feita através da atividade prática desenvolvida neste protejo, considerando assim que a elevação nos acertos tenha sido influenciada por isso.

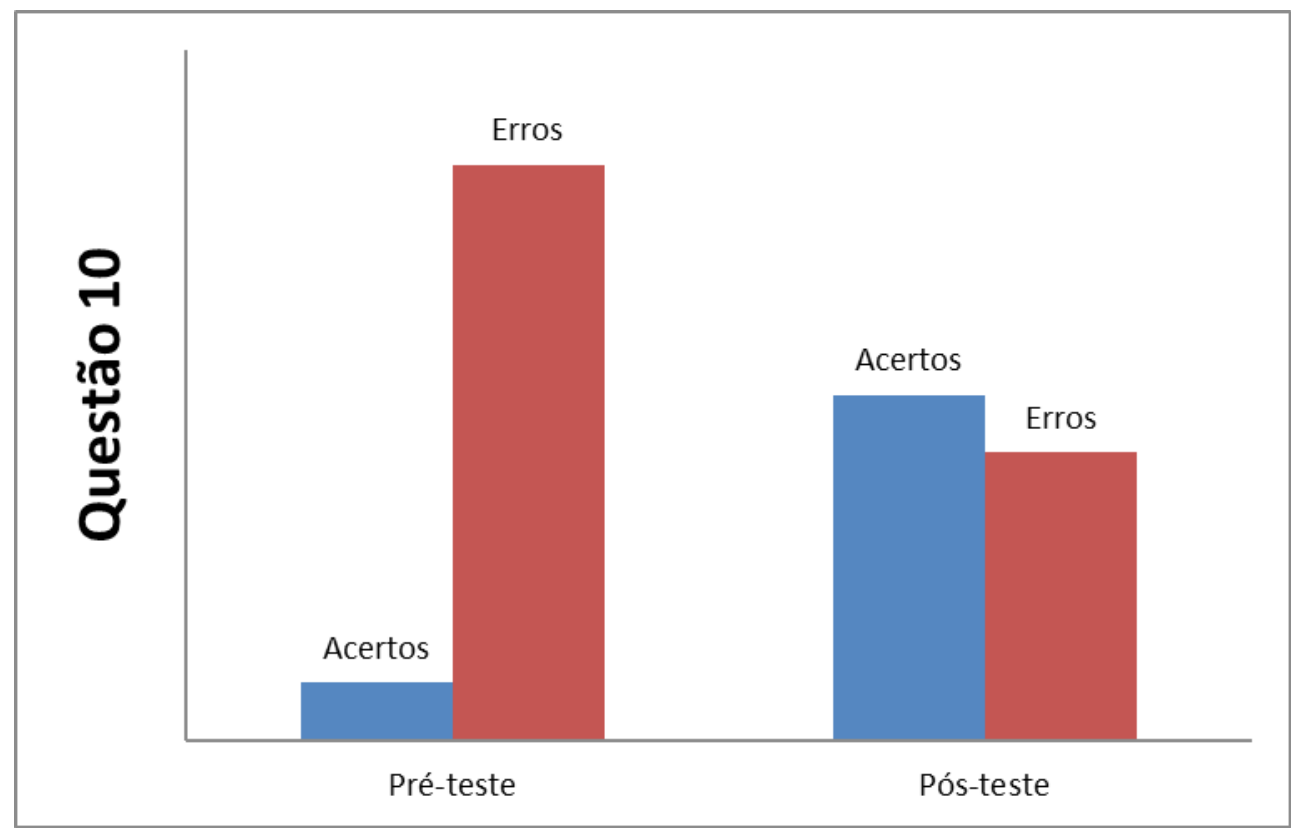

FIGURA 7: Gráfico referente à quantidade de acertos e erros na questão 10 do pré e pós-teste aplicados aos estudantes do $2^{\circ}$ ano da turma do EJA.

Durante essa atividade prática percebeu-se que alguns alunos já conheciam a localização de cada estrutura e sua função. Houve grande interesse e curiosidade dos estudantes em participar e manusear os modelos anatômicos. O uso deste recurso é bastante aconselhado para a abordagem dos conteúdos relacionados a anatomia humana, pois sua utilização é positiva no processo de construção do 
conhecimento, ocasionando uma melhor fixação das estruturas e do conteúdo (MORAES et al., 2016, p.226). Além disso outros autores também destacam o uso dos modelos anatômicos enquanto recursos pedagógicos:

Modelos anatômicos são peças tridimensionais similares às peças cadavéricas que podem ser confeccionados pelos próprios alunos, permitindo assim uma melhor visualização e manipulação (MORAES et al., 2016, p.226).

Os recursos didáticos propostos aliados às metodologias complementares supracitadas podem proporcionar um maior aprofundamento na busca pelo conhecimento e também levar a uma aproximação entre os estudantes e seus mestres. Uma atividade experimental que ofereça condições dos alunos confrontarem suas ideias e dúvidas sobre os fenômenos que ocorrem ao seu entorno. Não obstante, acredita-se ser uma maneira prazerosa de professor e aluno interagir e realizar o cumprimento de atividades experimentais, necessárias e estratégicas na formação dos alunos (PARANÁ, 2008 citado por FIGUEIRÓ; ROTHE, 2014, p.14).

O que chama mais atenção e serve até de alerta para os educadores é essa escassez de conhecimento em relação a anatomia levando-se em consideração que:

"conhecendo a biologia do corpo humano, pode contribuir para a formação da integridade pessoal e da autoestima, da postura de respeito a si próprio e aos outros, para o entendimento da saúde como um valor pessoal e social e para a compreensão da sexualidade humana sem preconceitos (BRASIL, 1996).

Maturana e Costa (2013, p. 4) ainda afirmam que:

"explorar a anatomia humana se faz imprescindível para o conhecimento e compreensão do corpo humano como um todo, independente da faixa etária, na importância e interação de todas as suas estruturas e características individuais dos seus órgãos, como meio essencial para promover a vida e cura dos males".

Todos os resultados expressos confirmam os dados já levantados por outros autores em relação ao ensino, que devido à complexidade de alguns assuntos, é preciso empregar metodologias mais dinâmicas e contextualizar o conteúdo. No entanto, normalmente os educadores não conseguem aplicá-las por causa da falta de recursos apropriados, ausência de laboratórios ou algum espaço para que o aluno possa vivenciar o conteúdo trabalhado em sala de aula (GUEDES, 2015).

\section{CONCLUSÃO}

O Estágio Curricular Supervisionado é uma etapa de grande importância para a carreira docente ao preparar o futuro professor para atuar neste meio. Nele, o estagiário se depara com as barreiras (falta de verba, material didático desatualizado, desarticulação do conteúdo, desvalorização da carreira, jornada de trabalho extensa...) que o professor enfrenta e que dificultam o processo de ensino aprendizagem. Nas escolas públicas essa realidade é nítida e acaba por favorecer a desmotivação dos alunos. 
Percebeu-se a necessidade da adoção de metodologias que despertem o interesse do aluno, contextualize o conteúdo com seu cotidiano e que não gere elevado custo financeiro. Na Educação de Jovens e Adultos (EJA) a necessidade de adoção de práticas dinamizadora é ainda maior. No EJA o professor tem que criar mais alternativas que consigam incentivar os estudantes a não desistir de estudar, visto que esse público geralmente possui uma idade avança e já chega cansado (e até atrasado) nas aulas ao ter que conciliar o trabalho com a rotina escolar.

O projetor multimídia (data-show) é uma ferramenta importante para o uso de imagens e esquemas diferentes dos livros didáticos, auxiliando o educando na compreensão de determinados assuntos, mas ele não deve ser usado como o único material. Além disso, ressalta-se a relevância dos modelos didático-pedagógicos como fonte de informações que criam significados e aproximação entre os conteúdos e os estudantes.

\section{REFERÊNCIAS}

BARBOSA, A.P.L.; RAMOS, P.P. SEREIA, D.A. O uso de modelos didáticos em aulas do sistema cardiovascular. In: Os estágios supervisionados de ciências e biologia em debate II, 2010, Cascavel. Anais... Cascavel, PR: UNIOESTE, 2010. Disponível em: <http://cacphp.unioeste.br/eventos/anais_biologia/estagio_ciencia/artigo_14.pdf $>$. Acesso em: 15 fev. 2018.

BRASIL. Lei de Diretrizes e Bases da Educação Nacional, Lei n 9394, 20 de dezembro de 1996. Brasília: MEC/SEF, 1996.

Secretaria de Educação. (PCN) Parâmetros Curriculares Nacionais: Ciências Naturais. Brasília: MEC/SEF, 1998.

CHASSOT, A. Alfabetização científica: uma possibilidade para a inclusão social. Revista Brasileira de Educação, n.22, p.89-100, 2003.

EVARISTO, D.C.S.; MENEZES, T. M.; SILVA, D. M. S.; SILVA, K. R. S.; CRUZ, J. E. S.; BRITO, V. C. Anatomia humana para todos: contribuindo para a compreensão do corpo humano. In: Jornada De Ensino, Pesquisa e Extensão, XIII, 2013, Recife. Anais... Recife, PE: UFRPE, 2013.

FIGUEIRÓ, J.P.S.; ROTHE, S.R. Modelos anatômicos como recurso didático em aulas práticas de Ciências e Biologia. 2014. 56p. TCC (Graduação em Ciências Biológicas) - UNIVERSIDADE FEDERAL DO PARANÁ, Curitiba, 2014.

FRACALANZA, H.; AMARAL, I.A.; GOUVEIA, M.S.F. 0 ensino de ciências no primeiro grau. São Paulo: Atual, 1987.

FREITAS, A.C.O. Utilização de recursos visuais e audiovisuais como estratégia no ensino da biologia. 2013. 50p. TCC (Graduação em Ciências Biológicas) Universidade Estadual do Ceará, Centro de Ciências da Saúde, Ceará, 2013.

GUEDES, M.R.A. Ensino de anatomia e fisiologia do sistema digestório humano mediado por sala ambiente. 2015. 70p. Dissertação (Mestrado em 
Ciências da Saúde e do Meio Ambiente) - Fundação Oswaldo Aranha Centro Universitário de Volta Redonda, Volta Redonda, 2015.

MACIEL, E.M.; MENDES; B.M.M. O estágio supervisionado na formação inicial: algumas considerações. In: Encontro de Pesquisa em Educação, do Encontro de Pesquisa em Educação, 2010. Teresina. Anais... Teresina, PI: UFPI, 2010.

MAFUANI, F. Estágio e sua importância para a formação do universitário. Instituto de Ensino superior de Bauru. 2011.

MATURANA, L.G.; COSTA, J.S.R. Anatomia humana como proposta práticopedagógica para aplicar o tema transversal saúde na rede estadual de ensino de Diamantina - MG. Revista Vozes dos Vales da UFVJM: Publicações Acadêmicas, n.03, ano II, 2013.

MORAES, G.N.B.; SCHWINGEL, P.A.; SILVA JÚNIOR, E.X. Uso de roteiros didáticos e modelos anatômicos, alternativos, no ensino-aprendizagem nas aulas práticas de anatomia humana. Rev. Ibero-Americana de Estudos em Educação, v.11, n.1, 2016.

PELOZO, R.C.B.; Prática de Ensino e Estágio Supervisionado enquanto mediação entre ensino, pesquisa e extensão. Faculdade de Ciências Humanas de Garça FAHU/FAEF, Garça/SP, 2007.

SANTOS, D.S. A importância do estágio para a vida acadêmica e profissional do aluno. 2014. Disponivel em: <https://www.portaleducacao.com.br/conteudo/artigos/iniciacao-profissional/a importancia-do-estagio-para-a-vida-academica-e-profissional-do-aluno/58044>. Acesso em: 17 fev. 2018.

SEDUCE - Secretaria de Estado da Educação, do Estado de Goiás. Currículo Referência da Rede Estadual de Educação de Goiás. Goiânia, 2012. Disponível em: <http://www.seduc.go.gov.br/imprensa/documentos/arquivos/Curr\%C3\%ADculo \%20Refer\%C3\%AAncia/Curr\%C3\%ADculo\%20Refer\%C3\%AAncia\%20da\%20Rede \%20Estadual\%20de\%20Educa\%C3\%A7\%C3\%A30\%20de\%20Goi\%C3\%A1s!.pdf>. Acesso em: 20 jan. 2018.

SILVA, E.P.Q.; CICILLINI, G.A. Das noções de corpo no ensino de biologia aos dizeres sobre sexualidade. 2008.

TRIVELATO, S.L.F. Ensino de ciências e o movimento CTS (ciência/ tecnologia/ sociedade). Coletânea da $3^{a}$ Escola de Verão para professores de Prática de Ensino de Física, Química e Biologia, p.122-130, 1995. 